\title{
How to Protect Young People from Social Drug Addiction
}

Nugzar GA*

Tbilisi State University, Georgia

*Corresponding author: Nugzar G Aleksidze, Member of Georgian National

Academy of Sciences, Tbilisi State University, Georgia, Email:

\section{Opinion}

Volume 3 Issue 6

Received Date: August 08, 2018

Published Date: August 18, 2018

aleksidze.nugzar@yahoo.com

\section{Opinion}

The negative impact of mobile phones and the Internet on people of all ages, evokes disorders of a circadian rhythm, insomnia, a risk of epilepsy, an aggression to the members of his/her family, a social isolation and an estrangement (one of the signs of autism). This phenomenon we called "a social drug addiction". It is necessary to create a serious legal act for protecting our children and grandchildren from the formation of this severe disease - a social drug addiction.

In recent years all over the world 5-6 year old children, students, young people and even older people actively use the Internet and mobile phones to get different information. Unfortunately, people of all ages, women and men are very attached to their mobile phones in public transport, during the rest, at home, theaters and even at opera and, apparently, they do not realize that they are gradually becoming dependent on mobile phones, as well as dependent on drugs. At present it becomes evident that mobile phones appear to be a social narcotic (drug) and young people become "drug addicts". Unfortunately, no one talks about the harm caused by the unlimited use of the Internet and mobile phones to people's health, especially to young people. Scientists have proved that the use of mobile phones for a long time because of information stress evokes the formation of aggressive mood in young people. If someone takes off the mobile from the child, one will clearly see his/her aggressive attitude in response to your action.

It is completely unreasonable the usage of mobile phones and the Internet by children and young people all day long. In such conditions the structural and functional formation of the young people brain is inhibited and damaged, and an aggressive mood is formed in the young people. It is known that the serious chemical changes in the blood and urine of children are observed while using mobile phones during one hour, and in adolescents - after two hours. Of course, all this is related to the psycho emotional load. During working with mobile phones for a long time the damage to vision is noted and there appears the risk of epilepsy development. Social drug addiction appears to be one of the damaging factors to behavior of teenagers. As a result of parents survey, I has been convinced that the young people stop reading books, have the disorder of a circadian rhythm, insomnia, and as a result they are late for their classes, and what is the most important, an aggressive attitude to their parents and social isolation from them have been observed in their behavior. They are so attached to mobile phones that such a behavior has been called "a social drug addiction". As far as I know, the use of mobile phones is forbidden in many schools of Europe, Russia and France, as the schoolchildren should have a rest in the intervals between lessons and not use their mobile phones. Some countries have forbidden the use of Internet by the population on weekends for the introduction of a healthy lifestyle.

The state, public schools administration and parents should pay a serious attention to the introduction of a healthy lifestyle. This will assist us to protect our children and grandchildren from this severe disease - a social drug addiction ("Sakartvelos Respublika", 2.08.2018, a newspaper "The Republic of Georgia"). 